\title{
TRANSAÇÕES E ESTRUTURAS DE GOVERNANÇA EM ORGANIZAÇÕES COOPERATIVAS NA ATIVIDADE LEITEIRA DO TERRITÓRIO CANTUQUIRIGUAÇU/PR
}

\author{
Anderson Sartorelli ${ }^{1}$ \\ João Armando Dessimon Machado² \\ Leonardo Xavier da Silva ${ }^{3}$
}

\begin{abstract}
Resumo
Amparado pelo aporte teórico da Economia dos Custos de Transação (ECT) e utilizando o método de Análise Estrutural Discreta Comparada (AEDC) para interpretação dos dados, o objetivo do artigo é analisar as estruturas de governança que predominam nas transações realizadas pelas organizações cooperativas de produção de leite no território Cantuquiriguaçu/PR. A investigação de campo revelou a existência de três grupos distintos de cooperativas neste território. Um primeiro composto por sete cooperativas ativas na captação de leite, com operações a montante e a jusante na atividade. Outro composto por três cooperativas não ativas na captação de leite, mas atuantes junto aos seus associados. E um terceiro composto por três cooperativas que haviam sido liquidadas, as quais foram descartadas do estudo pela impossibilidade de contato com algum dos responsáveis legais. Nas três cooperativas não ativas, a investigação identificou que a concorrência de mercado (preços, pressão de outras empresas etc.), a falta de agregação de valor ao produto, o baixo poder de negociação e o oportunismo dos agentes foram considerados fatores determinantes na decisão destas em encerrarem a atividade de captação de leite na região. Já a investigação sobre aquelas cooperativas que permaneciam ativas na captação de leite revelou que a estrutura de governança que predomina em suas transações é a bilateral ou também classificada como híbrida, baseada em relações contratuais predominantemente informais e do tipo relacional. Utilizando o método da AEDC, pôde-se concluir que essa forma de governança observada nas cooperativas ativas está em concordância com as indicações teóricas da ECT.
\end{abstract}

Palavras-chave: Agricultura familiar. Organizações cooperativas. Pecuária leiteira. Estrutura de governança.

1 Doutorando em Desenvolvimento Rural na Universidade Federal do Rio Grande do Sul (PGDR/UFRGS). Mestre em Desenvolvimento Rural pela Universidade Federal do Rio Grande do Sul (PGDR/UFRGS). Graduado em Economia pela Universidade Federal da Fronteira Sul (UFFS). E-mail: anderson.sartorelli@hotmail.com

2 Doutor em Economia Agroalimentar pela Universidade de Córdoba/Espanha. Mestre em Economia Rural pela Universidade Federal do Rio Grande do Sul (UFRGS). Graduado em Medicina Veterinária pela Universidade Federal do Rio Grande do Sul (UFRGS). Professor do Departamento de Economia e Relações Internacionais (DERI) da Universidade Federal do Rio Grande do Sul (UFRGS).E-mail: joao.dessimon@ufrgs.br

3 Doutor em Economia pela Universidade Federal do Rio Grande do Sul (UFRGS). Mestre em Economia Rural pela Universidade Federal do Rio Grande do Sul (UFRGS). Graduado em Economia pela Pontifícia Universidade Católica do Rio Grande do Sul (PUC-RS). Professor do Departamento de Economia e Relações Internacionais (DERI) da Universidade Federal do Rio Grande do Sul (UFRGS).E-mail: leonardo.xavier@ufrgs.br 


\section{Introdução}

A produção de leite no Brasil, assim como a maioria dos setores ligados ao agronegócio nacional, passou por significativas transformações estruturais ao longo das últimas duas décadas. A abertura comercial, juntamente com a liberalização dos preços a partir de 1990 provocou irreversíveis mudanças no setor leiteiro brasileiro, acelerando os movimentos de intensificação e utilização de novas tecnologias de produção, conduzindo-o a uma concentração industrial, especialmente, pela entrada de empresas multinacionais no país, além do surgimento de novas exigências de mercado (nacional e internacional), sobretudo em relação à qualidade do leite que vinha sendo produzido. Esse cenário intensificou a concorrência entre os diversos agentes produtivos e impactou diretamente na forma como o setor passou a ser organizado (WILKINSON, 1996).

A partir da referida conjuntura, a sobrevivência e a manutenção dos produtores de leite, de modo geral, e especialmente aqueles com negócios de caráter familiar passam a depender da capacidade de se intensificar a geração e a agregação de valor da sua produção. A maioria das estratégias de agregação de valor decorre, obrigatoriamente, pela criação e gestão de formas associativas que reúnam grupos de agricultores familiares com objetivos comuns no meio rural (BATALHA, BUAINAIN; SOUZA FILHO, 2005).

Dentre as formas associativas, destacam-se as organizações cooperativas. Essas organizações, conforme Sangalli et al. (2015), funcionam como mecanismos de minimização de barreiras ao crescimento da produção agrícola e possibilitam incrementos na renda dos agricultores, além de produzirem uma série de efeitos diretos e indiretos que contribuem com a dinamização do sistema socioeconômico e o desenvolvimento da região na qual estão inseridas.

Entretanto, ao mesmo tempo em que as organizações cooperativas se apresentam como alternativas viáveis aos agricultores, elas acabam enfrentando desafios quanto à sua atuação e permanência no mercado, especialmente relacionados às formas de gestão e governança. Batalha, Buainain e Souza Filho (2005) dividem esses desafios em dois aspectos: o primeiro aspecto, referente à operacionalização de técnicas eficientes no gerenciamento das transações, a montante e a jusante da cadeia de produção; o segundo, refere-se à gestão interna, ou seja, envolve as relações dos associados com a própria organização cooperativa. Este último é destacado pelos autores como condição fundamental para que os agricultores possam se valer das externalidades positivas proporcionadas por este tipo de organização no meio rural.

Brandão e Breitenbach (2019), em estudo realizado com cooperativas do Sul do Brasil, assinalam os principais problemas encontrados em relação 
à gestão e governança dessas organizações. Estes são: a) as cooperativas acabam competindo com outras empresas do setor e devem ser competitivas e ao mesmo tempo fiéis aos princípios cooperativistas; b) a gestão da cooperativa encontra dificuldade de atuar e competir em mercados oligopolizados; c) a participação dos cooperados na gestão é baixa; d) os associados e os gestores acabam exibindo comportamentos oportunistas.

Dos principais problemas enfrentados pelas cooperativas, observa-se que aqueles derivados da relação estabelecida com os membros associados acabam recebendo destaque. $\mathrm{O}$ gerenciamento dessas relações, por vezes conflituosa, se torna um dos principais gargalos a serem enfrentados pelos gestores das cooperativas. Motivados por esses elementos, o presente artigo realiza uma investigação em organizações cooperativas ligadas à atividade leiteira para analisar as principais estruturas de governança que vêm sendo adotadas por essas organizações na produção de leite do território ${ }^{4}$ Cantuquiriguaçu ${ }^{5}$ no estado do Paraná

Para tal investigação, o artigo toma os fundamentos da Nova Economia Institucional (NEI), mais especificamente o seu nível microanalítico, referente à Economia dos Custos de Transação (ECT) e as estruturas de governança como aportes teóricos para balizar a pesquisa. A NEI vem sendo considerada por alguns autores, como Zylbersztajn (1995) e Miguez (2011), uma abordagem interdisciplinar por considerar elementos e ferramentas de análise de diversas áreas do conhecimento, como a Sociologia, o Direito, a Psicologia e a Economia. Nesse sentido, Miguez (2011) ressalta que a NEI tem assumido esse papel interdisciplinar nas Ciências Sociais, por entender que a realidade social e econômica não pode ser analisada de forma compartimentalizada.

O caráter interdisciplinar permite lançar um olhar ampliado sobre os diversos aspectos que envolvem as interações sociais e econômicas na cadeia produtiva do leite; ainda, possibilita observar desde características pessoais e comportamentais dos agentes até condicionantes do próprio ambiente institucional no qual ocorrem essas interações. Amparado por esses elementos, o presente artigo objetivou identificar e analisar as estruturas de governança que predominam nas transações realizadas pelas organizações cooperativas de produção de leite a montante e a jusante no território Cantuquiriguaçu/PR.

\section{Fundamentos teóricos e conceituais da Economia dos Custos de Transação (ECT)}

O ponto de partida nas discussões sobre os custos de transação pode ser creditado a Ronald Coase, com seu clássico artigo The nature of the firm, publicado em 1937. O artigo lançou as bases da ECT ao questionar o modo como a firma era entendida sob a ótica da economia neoclássica.
4 A utilização do termo "território" abre espaço para uma ampla discussão em diversas áreas do conhecimento sobre seu conceito e aplicação. Como destaca Schneider (2009, p. 3), "[...] o conceito de território é ubíquo e amplo”. Assim, foge aos objetivos desse artigo entrar nesse profícuo debate, cabendo a utilização do termo território apenas para delimitar o universo empírico estudado, o qual é definido pela Política Territorial do Governo Federal.

5 O território Cantuquiriguaçu encontra-se localizado no Terceiro Planalto Paranaense e envolve um conjunto de 20 municípios: Laranjeiras do Sul, Nova Laranjeiras, Porto Barreiro, Rio Bonito do Iguaçu, Candói, Foz do Jordão, Reserva do Iguaçu, Pinhão, Marquinho, Goioxim, Cantagalo, Guaraniaçu, Diamante do Sul, Campo Bonito, Espigão Alto do Iguaçu, Ibema, Catanduvas, Três Barras do Paraná, Quedas do Iguaçu e Virmond (CONDETEC, 2011). 
Conforme Williamson (1989), os autores neoclássicos entendiam a firma como um espaço de transformações tecnológicas, no qual sua eficiência produtiva e econômica era dada unicamente por uma função de produção e por mecanismos de preços no mercado.

A principal contribuição de Coase (1937) foi afirmar que os mecanismos de preços apresentam falhas, modificando a maneira como a firma se comporta e alterando as ações dos agentes econômicos. Para o autor, existem custos para se acessar e, consequentemente, para se utilizar o mercado, e que estes custos vão além daqueles ligados à organização interna e de produção da firma. Essa nova forma de olhar a firma passa a considerar as relações organizacionais pautadas em acordos contratuais e os custos inerentes em tais acordos. Assim, advém de uma visão exclusivamente da produção e mecanismos de preços no mercado para incorporar também os custos relacionados às transações da firma.

Williamson (1989) considera as transações como a unidade básica de análise na ECT, a qual abrange um complexo de interações e compromissos intertemporais entre os agentes na forma de relações contratuais do ponto de vista legal. A existência de custos de transação demanda a criação e o desenvolvimento de instituições e estruturas de governança que garantam a continuidade dessas transações e os ajustes necessários das relações contratuais (WILLIAMSON, 1989).

A análise da ECT considera alguns elementos como subsídios fundamentais para melhor entender o funcionamento das organizações e suas formas de governança no mercado. Esses elementos são os pressupostos comportamentais dos agentes e as características/dimensões das transações.

Em relação às particularidades comportamentais dos agentes, Arbage (2004) destaca que estas são determinantes na forma como são desenhados os contratos (formais ou informais) e também na decisão por um ou por outro modo de governança. A ECT destaca dois principais pressupostos comportamentais em suas análises: a racionalidade e o oportunismo dos agentes.

A racionalidade limitada é abordada como um pressuposto cognitivo sobre o qual reside o comportamento humano nas transações (WILLIAMSON, 1989). No entendimento de Zylbersztajn (1995), a racionalidade limitada está em conformidade com o comportamento otimizador dos agentes econômicos. De tal modo, o agente deseja otimizar; contudo, dada sua capacidade limitada de receber, estocar, recuperar e processar as informações, nem sempre consegue satisfazer tal desejo. Simon (1978) afirma que os agentes econômicos desejam ser racionais e aperfeiçoar de maneira completa suas ações; entretanto, apenas conseguem fazer isso de modo limitado. Para este autor, isso decorre da falta tanto de informações completas quanto de habilidades computacionais perfeitas que 
impedem os agentes de tomarem a decisão racional e eficiente dentre todas possíveis (SIMON, 1978).

Com relação ao pressuposto do oportunismo dos agentes, Williamson (2012) entende-o como a busca do auto interesse de forma intencional e gananciosa. Nas palavras deste autor, “[...] o oportunismo refere-se à revelação incompleta ou distorcida da informação, aos esforços calculados de enganar, distorcer, disfarçar, ofuscar ou de outra forma confundir”(WILLIAMSON, 2012, p. 43). Torna-se, portanto, responsável pelas condições reais ou inventadas de assimetria de informações, que trazem complicações e geram os principais problemas das organizações econômicas (WILLIAMSON, 2012). Naturalmente, o conceito traz à luz uma conotação ética comportamental dos agentes, que, na teoria dos custos de transação, assume que estes podem agir de modo oportunístico. Vale ressaltar que esse pressuposto não significa que todos os agentes são de fato oportunistas, mas basta que alguns deles tenham a possibilidade de agir assim para que os acordos contratuais fiquem expostos a ações que demandam monitoramento (ZYLBERSZTAJN, 1995).

A ECT destaca ainda que a estrutura de governança pode ser influenciada diretamente pelas características e/ou dimensões, especificidade dos ativos, frequência e incerteza nas transações realizadas pelas organizações (WILLIAMSON, 1989). A especificidade dos ativos refere-se a quanto o investimento neste ativo é específico para determinada atividade e quão custoso é o seu emprego em uma atividade alternativa. $\mathrm{O}$ fato de haver ativos específicos pode gerar uma dependência bilateral e incorrer em complicações nas relações contratuais (WILLIAMSON, 1989). Os ativos específicos são classificados por Williamson (1993) em seis tipologias: os locacionais; os físicos; os humanos; os dedicados; os de marca; e os com especificidade temporal.

A frequência apresenta-se como importante dimensão da transação por dois aspectos principais: pela possibilidade de se construir uma boa reputação entre os agentes envolvidos e por proporcionar uma diluição dos custos inerentes a todas as transações (BANKUTI, 2007). Por fim, a incerteza está diretamente associada ao pressuposto da racionalidade limitada, e ao fato de estar relacionada à impossibilidade de se conhecer todos os eventos futuros que estão envolvidos nas transações da organização.

As dimensões das transações e os pressupostos comportamentais apresentados anteriormente representam os principais elementos utilizados pela ECT para estabelecer ou propor a estrutura de governança adequada capaz de reduzir os custos de transação da organização. Tais estruturas de governança são consideradas por Williamson (1989; 1996) como uma matriz institucional na qual as transações da organização são definidas e concretizadas. Essa matriz é entendida pelo autor, como o conjunto de 
leis, acordos contratuais, normas formais e informais e princípios internos às organizações responsáveis pela condução institucional da transação (WILLIAMSON, 1989).

A proposta apresentada por Williamson (1996) destaca que as estruturas de governança são mecanismos de coordenação que determinam o modo como as transações são configuradas e assumem três estruturas básicas: via mercado, hierárquica (integração vertical) e híbrida. O autor destaca que a governança de mercado e a hierárquica seriam os dois polos extremos entre os quais se encontrariam as demais formas de governança, tratadas pela ECT como sendo configurações híbridas.

A forma de governança, segundo a ECT, está diretamente relacionada com o problema dos contratos na economia. Williamson (1989) destaca que existe uma variedade de contratos, os quais podem ser explicados principalmente pelas diferenças presentes no conjunto dos atributos das transações. Nesse sentido, considerando as características das transações, cada forma de governança deve ser amparada por determinado tipo de contrato.

Williamson (1989) recorre aos trabalhos desenvolvidos por Macneil (1974, 1978) para classificar os contratos em: (a) clássicos, os quais são considerados contratos completos, padronizados e que se esgotam na hora da transação; (b) neoclássicos, aqueles considerados incompletos geralmente utilizados em transações de longo prazo por períodos determinados, sendo executados sob condições de incertezas, mas preservando a negociação entre as partes; e (c) relacionais, aqueles considerados incompletos e utilizados em transações que se repetem, não possuindo um período determinado, resultado basicamente do relacionamento e da confiança das partes. Sob essa perspectiva, pode-se estabelecer uma relação entre as estruturas de governança, os tipos de contrato, e as dimensões das transações (especificidade dos ativos, frequência e incerteza) na análise sob a ótica da ECT, conforme pode ser visualizado no Quadro 1.

Quadro 1 - Estrutura de governança, especificidade de ativos e frequência

\begin{tabular}{|c|c|c|c|}
\hline \multirow[b]{2}{*}{ Frequência } & \multicolumn{3}{|c|}{ Especificidade de ativos } \\
\hline & Baixa & Média & Alta \\
\hline Ocasional & & \multicolumn{2}{|c|}{$\begin{array}{c}\text { Governança trilateral } \\
\text { (Contratos neoclássicos) }\end{array}$} \\
\hline Recorrente & $\begin{array}{l}\text { Governança de mercado } \\
\text { (Contratos clássicos) }\end{array}$ & $\begin{array}{c}\text { Governança bilateral } \\
\text { (Contrato relacional ou neoclássico) }\end{array}$ & $\begin{array}{c}\text { Governança unificada } \\
\text { Ou hierárquica } \\
\text { (Contrato relacional) }\end{array}$ \\
\hline
\end{tabular}

Fonte: Adaptado de Williamson (1989, p. 87). 
De acordo com os preceitos da ECT, quando a especificidade dos ativos é baixa, os contratos clássicos são os mais apropriados, pois não há necessidade de cooperação entre as partes envolvidas na transação, ocorrendo via governança de mercado. A partir do momento em que aumenta a especificidade dos ativos e a frequência, os contratos tendem a ser neoclássicos ou relacionais, ocorrendo uma dependência bilateral. Quando as transações são ocasionais, adotam-se estruturas de governanças trilaterais, enquanto as transações recorrentes exigem uma governança bilateral. Se a especificidade dos ativos for tão alta e a transação recorrente que necessite ter uma governança hierárquica, essa transação será estabelecida sob contratos que possibilitem uma subordinação de uma parte sobre a outra (BANKUTI, 2007).

Zylbersztajn (1995) formulou um esquema analítico considerando os elementos da ECT e suas implicações na determinação da governança eficiente nas organizações, conforme pode ser visualizado na Figura 1, a seguir. Com relação às organizações em geral, em especial aquelas ligadas a setores agroindustriais, Zylbersztajn e Giordano (2015) salientam que estas passaram por profundas transformações nas últimas décadas, as quais deixaram de ser totalmente integradas verticalmente, para manterem, atualmente diversas relações de coordenação horizontal entre os setores primários e os industriais. Assim, as formas de governança se complexificaram e passaram a depender de uma gama de fatores que permeiam o ambiente organizacional.

Figura 1 - Esquema de Indução de Governança proposto por Zylbersztajn

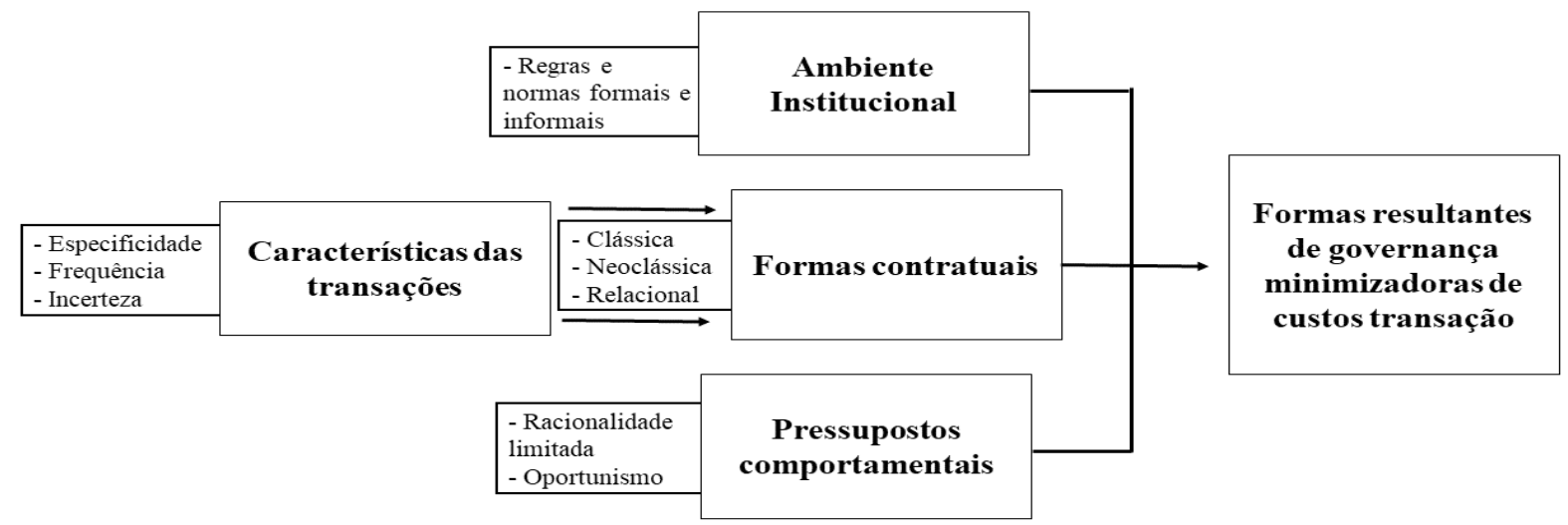

Fonte: Adaptada de Zylbersztajn (1995, p. 23). 
As características das transações, em especial a especificidade de ativos e a frequência, levam a diferentes alternativas de contratação, e estas, por sua, vez também são influenciadas pelos pressupostos da racionalidade limitada e do oportunismo dos agentes que estão inseridos em um ambiente institucional com regras formais e informais a serem cumpridas. Esses elementos são os condicionantes que interferem diretamente na escolha de determinada estrutura de governança (ZYLBERSZTAJN, 1995).

No caso das cooperativas agropecuárias, é importante não só compreender como ocorrem os processos de governança, mas também em que medida a racionalidade limitada e o oportunismo dos agentes podem interferir sobre seu sucesso ou gerar a descredibilidade da cooperação. Essa ótica de análise torna-se cada vez mais relevante para estudos rurais, ao passo que se observa crescente redução no interesse em cooperar e a presença de possíveis comportamentos oportunistas entre os agentes envolvidos na cadeia leiteira. Analisar as cooperativas pela ótica da ECT pode permitir a compreensão necessária das relações em curso no ambiente institucional e apontar pistas interessantes para pensar ações que visem ao desenvolvimento junto a essas organizações.

\section{Procedimentos metodológicos}

A pesquisa consiste em uma investigação de caráter exploratória e descritiva, realizada por meio de um estudo de múltiplos casos com organizações cooperativas na atividade leiteira do território Cantuquiriguaçu no Estado do Paraná. Definiu-se como unidade e/ou objeto de análise as transações realizadas pelas cooperativas, tanto no setor a montante com os produtores associados quanto a jusante com os parceiros comerciais e compradores do leite. De forma ilustrativa e sintética, essas relações estão ilustradas na Figura 2.

Figura 2 - Esquema representativo do objeto e unidade de análise da pesquisa

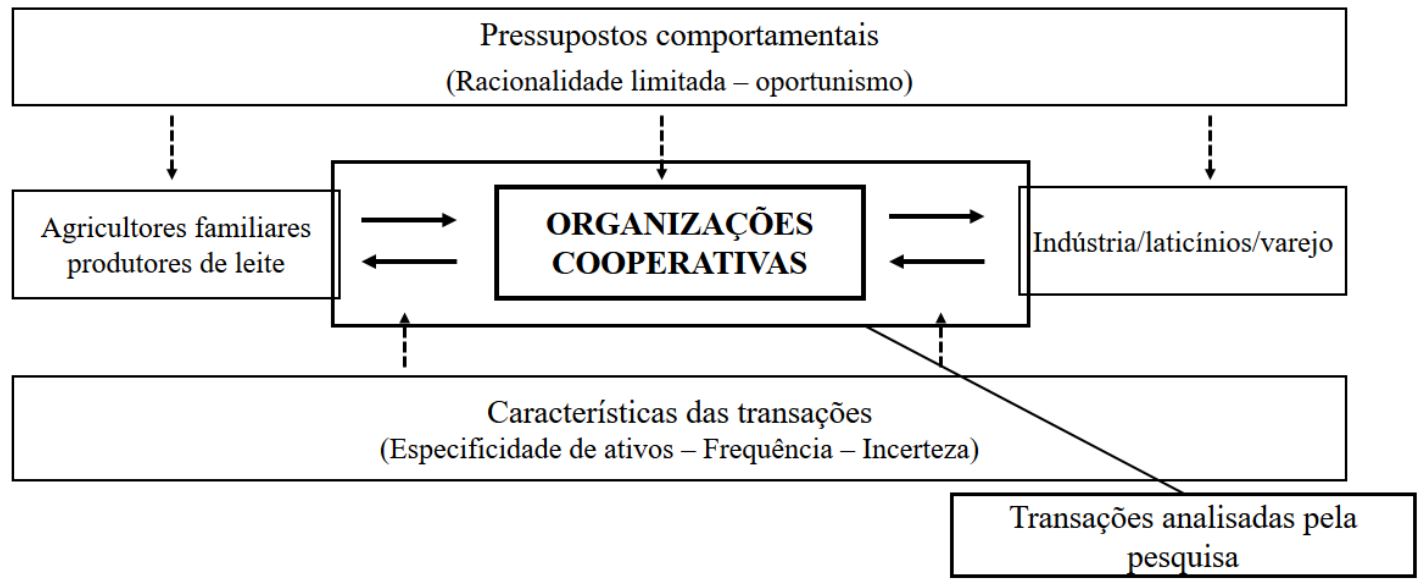

Fonte: Elaborada pelos autores (2017). 
Foram realizadas cinco entrevistas exploratórias não estruturadas com o objetivo de levantar o número de organizações cooperativas que atuavam na cadeia produtiva do leite do território Cantuquiriguaçu. Foram entrevistados três técnicos de extensão rural, um secretário de agricultura municipal e um produtor de leite, todos ligados diretamente à atividade leiteira. Essa investigação inicial ocorreu em dezembro de 2015 e revelou que havia um total de 13 organizações cooperativas atuando na produção e comercialização do leite da região.

A etapa seguinte de contatar as organizações e agendar as entrevistas revelou que três das 13 cooperativas haviam sido liquidadas, encerrando suas atividades. Dessa forma, a sequência da pesquisa contou com um universo de dez cooperativas a serem estudadas. Outra particularidade do estudo foi o fato de que, dentre estas dez, apenas sete se encontravam efetivamente ativas e realizando transações na captação e comercialização do leite de seus associados. As outras três cooperativas haviam encerrado as atividades de captação de leite; porém, permaneciam ativas realizando algum tipo de transação com seus associados, seja por meio de venda de insumos e assistência técnica/veterinária e/ou auxiliando-os na comercialização no mercado.

O Quadro 2 apresenta os três grupos de cooperativas encontradas durante a investigação de campo, a qual ocorreu em janeiro, fevereiro e março de 2016, além de identificá-las com os pseudônimos adotados na pesquisa.
6 Para a identificação das organizações, adotaram-se os pseudônimos de cooperativa A, cooperativa $\mathrm{B}$, cooperativa C etc. para identificar as 13 cooperativas estudadas. Esse ordenamento alfabético seguiu a cronologia de fundação das organizações, sendo a cooperativa $\mathrm{A}$, a primeira a ser instituída na região.

Quadro 2 - Situação das organizações cooperativas no território Cantuquiriguaçu em 2016

\begin{tabular}{|l|l|}
\hline Cooperativas & \\
\hline Coop. A & Ativa nas transações a montante e a jusante na atividade leiteira \\
\hline Coop. $\mathrm{B}$ & Ativa nas transações a montante e a jusante na atividade leiteira \\
\hline Coop. $\mathrm{C}$ & Não ativa na captação de leite, mas com atividades de venda de insumos e assistência técnica aos associados \\
\hline Coop. $\mathrm{D}$ & Liquidada/extinta \\
\hline Coop. $\mathrm{E}$ & Ativa nas transações a montante e a jusante na atividade leiteira \\
\hline Coop. $\mathrm{F}$ & Ativa nas transações a montante e a jusante na atividade leiteira \\
\hline Coop. $\mathrm{G}$ & Ativa nas transações a montante e a jusante na atividade leiteira \\
\hline Coop. $\mathrm{H}$ & Liquidada/extinta \\
\hline Coop. $\mathrm{I}$ & Ativa nas transações a montante e a jusante na atividade leiteira \\
\hline Coop. $\mathrm{J}$ & Ativa nas transações a montante e a jusante na atividade leiteira \\
\hline Coop. $\mathrm{K}$ & Liquidada/extinta \\
\hline Coop. $\mathrm{L}$ & $\begin{array}{l}\text { Não ativa na captação de leite, mas com atividades de venda de insumos e serviços de resfriamento de leite } \\
\text { às indústrias da região }\end{array}$ \\
\hline Coop. $\mathrm{M}$ & $\begin{array}{l}\text { Não ativa na captação de leite, mas ainda representa os associados junto às indústrias que compram o leite } \\
\text { no município }\end{array}$ \\
\hline
\end{tabular}

Fonte: Elaborado pelos autores com dados da pesquisa de campo (2017). 
Identificadas as cooperativas atuantes, realizou-se uma entrevista semiestruturada com o gestor (atual presidente) de cada uma das organizações propostas no estudo. Como houve dois casos específicos entre as cooperativas, a coleta de dados foi adaptada da seguinte forma: as entrevistas realizadas nas três cooperativas não ativas na captação buscaram caracterizá-las e, em especial, identificar os motivos que as levaram à decisão de encerrar a atividade de captação de leite junto aos seus associados. As entrevistas realizadas nas sete cooperativas ativas na captação de leite objetivaram apreender informações que permitissem, à luz da ECT, caracterizar e analisar as transações realizadas e identificar, dessa forma, as estruturas de governança predominantes.

A entrevista aplicada nas cooperativas ativas da captação do leite foi composta por questões abertas e fechadas. As questões fechadas foram estruturadas utilizando o modelo de mensuração conhecido como escala Likert. Essa escala foi adotada por possibilitar captar/mensurar a percepção dos entrevistados em relação às principais características das transações e ainda apreender sobre os pressupostos comportamentais dos agentes que as realizavam. De acordo com Malhotra (2006), esse tipo de escala possui pontos de quebra entre os extremos que possibilitam avaliar graus de concordância, de satisfação ou importância sobre o objeto pesquisado.

Para a identificação e análise das estruturas de governança, utilizouse como método de interpretação dos dados a Análise Estrutural Discreta Comparada (AEDC) (WILLIAMSON, 1991). O método AEDC permite comparar, como em duas fotografias, o modelo de governança encontrado na realidade, ou seja, aquele que vem sendo adotado pela organização comparado com o modelo considerado ideal, o qual - balizado pela teoria da ECT - seria o minimizador de custos de transação.

\section{Resultados e discussões}

Os resultados e as discussões do artigo estão organizados em dois blocos. O primeiro bloco, na seção 4.1, apresenta os resultados da investigação realizada nas organizações cooperativas $(\mathrm{C}, \mathrm{L}, \mathrm{M})$, as quais não se encontravam ativas na captação do leite, embora permanecessem atuantes no setor, realizando outras atividades. A investigação nesse grupo de cooperativas revelou os principais motivos que culminaram na decisão do encerramento da captação de leite junto ao produtor. $\mathrm{O}$ segundo bloco, na seção 4.2 apresenta os resultados encontrados nas cooperativas ativas na captação do leite, enfatizando as características de suas transações, os pressupostos comportamentais dos agentes e os tipos de contratos, para a análise e identificação das estruturas de governança utilizadas. 
Motivos determinantes do encerramento da atividade de captação de leite nas cooperativas " $C$ " " $L$ " e " $M$ "

As três cooperativas em questão foram constituídas por meio da organização dos produtores e com o apoio de órgãos públicos, como EMATER e secretarias de agricultura dos municípios. O objetivo inicial de constituição de ambas foi o de aumentar o poder de barganha dos produtores frente ao mercado comprador de leite na região. A cooperativa “C” foi fundada em 1999 e atuou até 2011 (12 anos) na captação do leite; no momento de encerramento, possuía um quadro social de 64 produtores associados e comercializava em média 600 mil litros de leite mensais. A cooperativa "L" teve sua fundação em 2008 e atuou até 2013 (cinco anos); possuía 35 associados ativos e comercializava cerca de 275 mil litros de leite mensais. E a cooperativa "M" iniciou suas atividades em 2009 e atuou na captação de leite até 2015 (seis anos); possuía 60 produtores associados e comercializava cerca de 120 mil litros de leite mensais. As três cooperativas realizavam operações de captação de leite in natura nas propriedades, resfriamento e venda no mercado spot. $\mathrm{O}$ pagamento ao produtor associado era realizado, principalmente, pela quantidade de leite e, em seguida, pela qualidade que este apresentava.

Com relação aos tipos de contratos realizados, as cooperativas " $\mathrm{C}$ " e "M" operavam apenas com acordos contratuais informais, tanto com os seus produtores associados quanto com os compradores do seu leite no mercado spot, ou seja, não existiam amarras formais em suas negociações. Já a cooperativa "L" possuía acordos contratuais formalizados com seus associados, as quais determinavam algumas regras nas negociações. Por outro lado, suas relações com os compradores do leite no mercado se davam totalmente de maneira informal. Segundo relatado nas entrevistas, os acordos formais no mercado do leite se tornam caros e difíceis de manter, principalmente pela volatilidade dos preços, em decorrência da oferta e da demanda, e por ser um produto perecível.

A investigação nas cooperativas não ativas na captação de leite revelou os principais motivos que as levaram à decisão de encerrar essa atividade junto aos seus associados, conforme pode ser visualizado na Figura 3 que apresenta uma nuvem de palavras que mais se repetiram durante as entrevistas. 
Figura 3 - Principais motivos que contribuíram na decisão de as cooperativas encerrarem as atividades de captação de leite

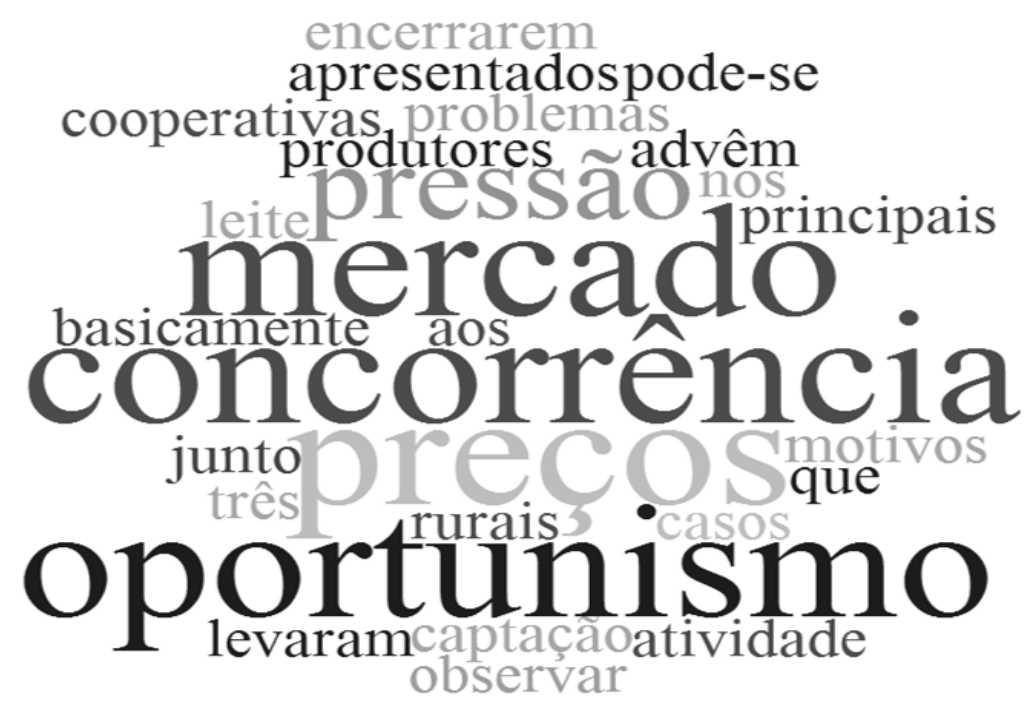

Fonte: Adaptada de WordClouds (2017).

Conforme observado na Figura 3, a concorrência no mercado (preços, pressão de outras empresas etc.), a falta de agregação de valor ao leite e o baixo poder de negociação por preços, e o oportunismo dos agentes foram considerados, pelos respondentes, como os principais motivos que levaram as cooperativas a encerrarem as atividades de captação de leite. De acordo com o aporte teórico aqui utilizado, o oportunismo confirma-se enquanto um dos elementos que conduzem ao encerramento das atividades cooperativas, especialmente nas relações mercantis. Os elementos encontrados vão ao encontro dos achados por Zylbersztajn (1995), em seu estudo sobre estruturas de governança e coordenação no sistema agroindustrial do café, o qual aponta que as relações e as transações das organizações são influenciadas diretamente pelo ambiente institucional no qual estão inseridas e pelos pressupostos comportamentais dos agentes envolvidos.

A competitividade no ambiente institucional também foi apontada por Simioni et al. (2009) como um dos elementos responsáveis pela permanência das cooperativas agropecuárias nos Estados de Santa Catarina, Paraná e São Paulo. O autor identificou comportamentos desleais e oportunistas entre os diversos agentes da cadeia produtiva do leite ligados a cooperativas. Dessa forma, a competitividade do ambiente institucional aliada aos pressupostos comportamentais implica a necessidade de as organizações cooperativas construírem relações de lealdade e confiança com seus associados. 
Dentre os motivos levantados pela pesquisa para a decisão de as cooperativas encerrarem as atividades de captação de leite, o oportunismo dos agentes, especialmente o presente nas transações com os produtores associados, recebe destaque. De acordo com os representantes entrevistados, esse é um problema que agrava a situação das cooperativas, uma vez que, mesmo com esforços para a fidelização dos associados, estes estão susceptíveis à variação e à oferta de preços por outras empresas. Dessa forma, como as cooperativas em questão necessitavam de volume de leite para aumentar suas margens, visto que atuavam apenas como "repassadoras" do produto, a evasão de seus associados para outras empresas privadas do setor lácteo acabou sendo um fator determinante para a decisão de encerrarem a captação de leite nas propriedades.

Com relação a esse desvio de conduta dos associados com a cooperativa, Zhang, Li e Huang (2017), em estudo realizado na China, apontam dois mecanismos de governança para minimizar seus impactos negativos: a formalização e a socialização. $O$ uso de um ou de outro mecanismo depende do tipo específico que levou ao desvio na transação, os quais podem ser de duas formas, por comportamentos oportunistas ou por questões mal-entendidas entre as partes. Assim, a socialização se torna mais eficaz do que a formalização nos relacionamentos quando o nível de oportunismo é alto, enquanto a formalização funciona melhor quando o nível de desentendimento é alto.

As organizaçôes cooperativas ativas na captação de leite junto aos seus associados

O Quadro 3 apresenta as principais características das organizações cooperativas ativas na captação de leite no território Cantuquiriguaçu e enfatiza as principais formas contratuais observadas nas transações para posterior análise das estruturas de governança. 
Quadro 3 - Características gerais e contratos nas organizações cooperativas ativas na captação de leite em Cantuquiriguaçu em 2016

\begin{tabular}{|c|c|c|c|c|c|}
\hline & Ano & $\begin{array}{l}\text { Motivos para } \\
\text { constituição da } \\
\text { cooperativa }\end{array}$ & $\begin{array}{l}\text { Operações } \\
\text { Realizadas } \\
\text { atualmente }\end{array}$ & $\begin{array}{l}\text { Tipos de Contratos nas } \\
\text { transações das cooperativas }\end{array}$ & $\begin{array}{l}\text { Pontos } \\
\text { considerados } \\
\text { importantes no } \\
\text { estabelecimento } \\
\text { dos contratos }\end{array}$ \\
\hline Coop. A & 1998 & $\begin{array}{l}\text { Estruturar a } \\
\text { atividade; } \\
\text { Busca por } \\
\text { melhores preços }\end{array}$ & $\begin{array}{l}\text { Coleta; } \\
\text { Resfriamento; } \\
\text { Comercialização }\end{array}$ & $\begin{array}{l}\text { Contratos informais do tipo } \\
\text { relacional, tanto nas transações } \\
\text { a montante quanto a jusante }\end{array}$ & $\begin{array}{l}\text { Estabelecimento } \\
\text { de preço; } \\
\text { Vigência; } \\
\text { Garantias de } \\
\text { recebimento }\end{array}$ \\
\hline Coop. B & 2000 & $\begin{array}{l}\text { Estruturar a } \\
\text { atividade; } \\
\text { Busca por } \\
\text { melhores preços }\end{array}$ & $\begin{array}{l}\text { Coleta; } \\
\text { Pasteurização; } \\
\text { Comercialização }\end{array}$ & $\begin{array}{l}\text { Contrato informal do tipo } \\
\text { relacional nas transações a } \\
\text { montante; } \\
\text { Contratos formais dos tipos } \\
\text { neoclássico e relacional a } \\
\text { jusante }\end{array}$ & $\begin{array}{l}\text { Estabelecimento } \\
\text { de preços; } \\
\text { Garantias de } \\
\text { pagamentos; } \\
\text { Vigência }\end{array}$ \\
\hline Coop. E & 2006 & $\begin{array}{l}\text { Estruturar a } \\
\text { atividade; } \\
\text { Autonomia na } \\
\text { comercialização }\end{array}$ & $\begin{array}{l}\text { Coleta; } \\
\text { Entrega direta } \\
\text { ao laticínio }\end{array}$ & $\begin{array}{l}\text { Contrato formal do tipo } \\
\text { relacional nas transações a } \\
\text { montante; } \\
\text { Contrato informal do tipo } \\
\text { relacional nas transações a } \\
\text { jusante }\end{array}$ & $\begin{array}{l}\text { Garantias de } \\
\text { recebimento; } \\
\text { Cláusula rescisória; } \\
\text { Estabelecimento } \\
\text { de preços }\end{array}$ \\
\hline Coop. F & 2005 & $\begin{array}{l}\text { Busca por } \\
\text { melhores } \\
\text { Preços; } \\
\text { Aumentar poder } \\
\text { de negociação }\end{array}$ & $\begin{array}{l}\text { Coleta; } \\
\text { Entrega direta } \\
\text { ao laticínio }\end{array}$ & $\begin{array}{l}\text { Contratos informais do tipo } \\
\text { relacional, tanto nas transações } \\
\text { a montante quanto a jusante }\end{array}$ & $\begin{array}{l}\text { Garantias de } \\
\text { recebimento; } \\
\text { Cláusula rescisória; } \\
\text { Estabelecimento } \\
\text { de preços }\end{array}$ \\
\hline Coop. G & 2005 & $\begin{array}{l}\text { Estruturar a } \\
\text { atividade; } \\
\text { Busca por } \\
\text { melhores preços }\end{array}$ & $\begin{array}{l}\text { Coleta; } \\
\text { Entrega direta } \\
\text { ao laticínio }\end{array}$ & $\begin{array}{l}\text { Contrato informais do tipo } \\
\text { relacional, tanto nas transações } \\
\text { a montante quanto a jusante }\end{array}$ & $\begin{array}{l}\text { Garantias de } \\
\text { recebimento; } \\
\text { Estabelecimento } \\
\text { de preços; } \\
\text { Vigência }\end{array}$ \\
\hline Coop. I & 2006 & $\begin{array}{l}\text { Aumentar } \\
\text { o poder de } \\
\text { negociação }\end{array}$ & $\begin{array}{l}\text { Coleta; } \\
\text { Entrega direta } \\
\text { ao laticínio }\end{array}$ & $\begin{array}{l}\text { Contrato informal do tipo } \\
\text { relacional nas transações a } \\
\text { montante; } \\
\text { Contrato formais dos tipos } \\
\text { relacional e neoclássico nas } \\
\text { transações a jusante }\end{array}$ & $\begin{array}{l}\text { Garantias de } \\
\text { recebimento; } \\
\text { Preços; } \\
\text { Vigência }\end{array}$ \\
\hline Coop.J & 2006 & $\begin{array}{l}\text { Melhorar os } \\
\text { preços; } \\
\text { Estruturar a } \\
\text { atividade leiteira }\end{array}$ & $\begin{array}{l}\text { Coleta; } \\
\text { Entrega direta ao } \\
\text { laticínio }\end{array}$ & $\begin{array}{l}\text { Contratos informais do tipo } \\
\text { relacional, tanto nas transações a } \\
\text { montante quanto a jusante }\end{array}$ & $\begin{array}{l}\text { Preços; } \\
\text { Cláusula rescisória; } \\
\text { Vigência }\end{array}$ \\
\hline
\end{tabular}

Fonte: Elaborado pelos autores com base nos dados de campo (2017). 
Conforme revela o Quadro 3, um ponto comum na constituição de todas as cooperativas refere-se à busca por melhores preços pelo leite no mercado. Esse produto encontrava-se desfavorável tendo em vista a alta concentração e dominação de poucas empresas compradoras, as quais detinham o controle sobre a compra e sobre os preços pagos aos produtores de leite.

Ressalta-se que, dentre os sete casos estudados, a cooperativa B é a única que realiza o beneficiamento do leite antes de comercializá-lo no mercado. Assim, o leite é coletado nas propriedades, transportado, armazenado, pasteurizado e empacotado em embalagens (saquinhos) de um litro, popularmente chamadas de "barriga mole", e distribuído em padarias e mercados locais, sendo vendido, ainda, para programas governamentais do Estado. As demais cooperativas apenas se restringem à coleta do leite nas propriedades, ao transporte, ao armazenamento e à comercialização do produto in natura com indústrias compradoras.

Características das transações e pressupostos comportamentais nas organizações cooperativas ativas na captação de leite

Os determinantes das estruturas de governança das organizações cooperativas ativas na captação de leite são divididos em dois blocos de análise. $\mathrm{O}$ primeiro bloco está relacionado às dimensões das transações com olhar sobre a especificidade dos ativos, a incerteza e frequência; o segundo, aos pressupostos comportamentais da racionalidade limitada e oportunismo dos agentes.

No que se refere à dimensão especificidades dos ativos, analisou-se a especificidade dos ativos em relação à exclusividade dos investimentos realizados pelas cooperativas para a atividade com o leite, a especificidade da mão de obra nas operações e a especificidade do próprio produto leite em relação à sua produção, ao seu armazenamento, à sua industrialização e ao seu transporte.

Dentre os casos investigados, destacam-se os investimentos em ativos realizados pela cooperativa $\mathrm{B}$ para viabilizar sua estrutura de beneficiamento do leite, os quais foram considerados altos e exclusivos, pelo fato de ser a única que industrializa a matéria-prima antes de comercializá-la. Nos demais casos, os investimentos se restringiram à compra de caminhões equipados para a coleta e o transporte do leite, de veículos utilitários, de equipamentos de escritório e para a estruturação das lojas de insumos agropecuários. Em relação à especificidade da mão de obra, todas as cooperativas entrevistadas consideram parcialmente ou totalmente possível sua utilização em outra atividade, alternativa ao leite. Sobre a especificidade temporal da atividade desenvolvida, todos os entrevistados consideraram o produto leite altamente específico, pois é perecível e demanda ser transportado e transacionado o 
mais rápido possível para não perder qualidade e. consequentemente, valor de mercado.

A especificidade temporal também foi apontada por Breitenbach (2008) em seu estudo sobre estruturas de mercado e governança na cadeia produtiva do leite no município de Ajuricaba/RS. A autora salienta para a necessidade de um processamento rápido do produto tendo em vista sua perecibilidade.

$\mathrm{Na}$ mesma linha dos resultados apresentados, Schubert e Waquil (2014), em estudo com cooperativas de leiteiras de Santa Catarina, também apontam para a alta especificidade dos ativos relacionados à produção de leite. E que este, por ser perecível, conduz à necessidade de um transporte ágil, não muito longo e de alto custo com resfriamento. Para os autores, a especificidade dos ativos foi um dos principais causadores de custos de transação.

A segunda característica das transações analisadas nas cooperativas refere-se a incertezas. Estas se encontram presentes nas transações a montante e a jusante, sendo percebidas pelos gestores das cooperativas. Contudo, embora percebendo a incerteza como geradora de custos nas transações, ainda faltam ações e organização para articular mecanismos de controle e monitoramento para minimizá-las. Esses resultados são semelhantes aos encontrados por Schubert e Waquil (2014), os quais também apontavam o conhecimento sobre as incertezas nas cooperativas de leite, mas não possuíam estratégias futuras para mitigá-las.

A última característica das transações investigada foi a sua frequência. Investigou-se o quão recorrentes são as transações das cooperativas com seus parceiros comerciais, seja com os produtores associados ou com compradores da sua produção. Com os associados, a frequência foi considerada alta e positiva pelos entrevistados, visto que as comodidades nas transações - como as condições diferenciadas de pagamento pelos produtos adquiridos e a prestação dos serviços nas propriedades - contribuem de forma significativa, além de haver, mensalmente, transações com a captação de leite e negociações por preços e pagamentos.

Do mesmo modo, a frequência das transações realizadas com os parceiros comerciais compradores do leite da cooperativa foi considerada alta pelos entrevistados. Essa frequência ocorre porque as transações e negociações são recorrentes e se repetem (diariamente, semanalmente). E, também, porque algumas cooperativas já estão há cinco e sete anos negociando o leite com os mesmos compradores, como é o caso das cooperativas B e I, respectivamente. A recorrência e a longevidade desses acordos e dessas transações podem ser consideradas positivos nas cooperativas e minimizadoras de custos de transação.

A ECT postula que existem pressupostos comportamentais envolvidos nas transações e determinantes de governança, que são: a 
racionalidade limitada e o oportunismo. No que tange à racionalidade limitada, investigou-se: a) a percepção dos representantes das cooperativas em relação às vantagens de estarem organizados de forma coletiva; b) a percepção sobre as fontes de coleta de informações; c) a importância destas informações nas decisões estratégicas; e d) o entendimento da eficiência da forma como a cooperativa vem atuando na atividade leiteira. A percepção dos entrevistados sobre esses elementos permite afirmar que o pressuposto da racionalidade limitada está presente nas cooperativas. Esse fato fica evidente quando os respondentes se contradizem ao afirmarem que, as cooperativas não então atuando com eficiência no mercado, mas, ao mesmo tempo, estão tomando as melhores decisões estratégias com informações satisfatórias.

Outro aspecto comportamental investigado foi o oportunismo dos agentes envolvidos nas transações com as cooperativas. Segundo os entrevistados, o oportunismo pode ser recorrente nas transações, tanto nas relações a montante quanto nas relações a jusante da cooperativa. De acordo com as respostas obtidas, o oportunismo se manifesta, por um lado, quando os associados decidem negociar o leite com outras empresas quando os preços lhes são favoráveis, deixando de vender para a cooperativa. E, por outro lado, quando voltam a procurar a cooperativa no momento em que quando os preços encontrados no mercado estão baixos. Outra forma de oportunismo relatado ocorre quando os associados desejam apenas negociar insumos e serviços de assistência técnica com a cooperativa por obterem alguma vantagem econômica.

Com relação aos compradores do leite, segundo os respondentes, o oportunismo se manifesta quando estes atrasam os pagamentos ou decidem negociar volumes menores do que havia sido combinado. Embora esses elementos possam variar de menor ou maior grau para os casos estudados, podem ser considerados elementos geradores de custos de transação para as organizações cooperativas.

Estruturas de governança nas organizações cooperativas ativas na captação de leite

As estruturas de governança, como destacado na seção teórica, são os mecanismos de coordenação que determinam o modo como as transações são configuradas pelas organizações dentro de um ambiente institucional.

As orientações teóricas destacam que a governança adequada pode ser estruturada considerando as seguintes particularidades: os contratos clássicos serão os mais apropriados quando a especificidade dos ativos for baixa, pois não haverá necessidade de cooperação 
entre as partes envolvidas na transação, esta que pode ocorrer via governança de mercado.

A partir do momento em que se aumenta a especificidade dos ativos e a frequência, os contratos tendem a ser neoclássicos ou relacionais ocorrendo uma dependência bilateral. Quando as transações são ocasionais, adotam-se estruturas de governança trilaterais, enquanto as transações recorrentes exigem uma governança bilateral. Se a especificidade dos ativos for tão alta e a transação recorrente que necessite ter uma governança hierárquica, essa transação será estabelecida sob contratos que possibilitem uma subordinação de uma parte sobre a outra. Com base nesse aparato teórico para determinar o modelo de governança eficiente, analisaram-se as estruturas presentes nas organizações cooperativas de produção de leite no território Cantuquiriguaçu.

Atendendo à orientação teórica de Williamson (1989), juntamente com sua classificação em governança em mercado, trilateral, bilateral e unificada, o Quadro 5 apresenta as relações entre especificidade dos ativos e frequência das transações encontradas nas cooperativas e o que seria considerada, de acordo com a ECT, a estrutura de governança adequada.

Quadro 5 - Governança eficiente à luz da ECT para o conjunto das cooperativas estudadas

\begin{tabular}{|c|c|c|c|}
\hline & \multicolumn{3}{|c|}{ Especificidade dos ativos nas cooperativas } \\
\hline Frequência & Baixa & Média & Alta \\
\hline Ocasional & \multirow[b]{2}{*}{$\begin{array}{l}\text { Governança de mercado } \\
\text { (Contratos clássicos) }\end{array}$} & \multicolumn{2}{|c|}{$\begin{array}{c}\text { Governança trilateral } \\
\text { (Contratos neoclássicos) }\end{array}$} \\
\hline Recorrente & & $\begin{array}{l}\text { Governança bilateral } \\
\text { (Contrato relacional) }\end{array}$ & $\begin{array}{c}\text { Governança unificada } \\
\text { ou hierárquica } \\
\text { (Contrato relacional) }\end{array}$ \\
\hline
\end{tabular}

Fonte: Adaptado de Williamson (1989, p. 87).

Devido à especificidade dos ativos ser considerada média e haver uma recorrência nas transações das cooperativas, pode-se inferir que a estrutura que mais se aproxima da adequada para estas seria uma governança bilateral, com o estabelecimento de contratos relacionais, com base em relações de confiança entre as partes. Isso decorre, principalmente, do grau de especificidade dos ativos encontrado, o qual não pode ser classificado nem como baixo, o que orientaria para uma governança via mercado, nem como alto, o que seria orientador para uma governança unificada (hierárquica). O grau médio de especificidade dos ativos e as dimensões das transações, aliados às características do produto leite, geram uma dependência bilateral para as cooperativas em relação aos seus parceiros comerciais. 
Essa dependência bilateral, especialmente nas transações a jusante, pode ser tratada como decorrente das próprias características em como estas transações são realizadas. Conforme relatado, a maioria das cooperativas não possui uma plataforma de armazenamento e resfriamento do leite, sendo este coletado nas propriedades rurais por caminhões com tanques isotérmicos e entregue diretamente às indústrias. Assim, as transações acabam gerando inseguranças e problemas de coordenação, pois qualquer sinistro ou evento não programado - por exemplo, um desacordo entre as partes ou mesmo uma recusa das indústrias em receber o leite - causaria perdas irreparáveis para à cooperativa, visto que o leite, por ser um produto perecível, não poderia ser reaproveitado em outra transação.

Como pôde ser observado no Quadro 5, apenas duas das três dimensões das transações foram consideradas por Williamson (1989) para determinar a eficiência da governança. Segundo o autor, a terceira dimensão, referente à incerteza, é pressuposta na análise com um grau suficiente para gerar problemas de decisões sequenciais, os quais causam necessidades de adaptação. Dessa forma, a dimensão da incerteza é considerada como presente, decorrendo, sobretudo, da racionalidade limitada dos agentes.

A partir dessa orientação teórica, das características das transações e dos pressupostos comportamentais, pode-se inferir que a estrutura de governança que mais se verificou no caso das cooperativas de leite do território Cantuquiriguaçu é a bilateral, baseada em relações contratuais predominantemente informais e do tipo relacional. Como pode ser observado na Figura 4, a qual apresenta uma adaptação do esquema de indução de governança proposto por Zylbersztajn (1995), há a combinação dos vários condicionantes que cercam as transações das cooperativas induzindo-as a essa organização e governança observada.

Figura 4 - Condicionantes de indução de governança nas cooperativas ativas na captação de leite

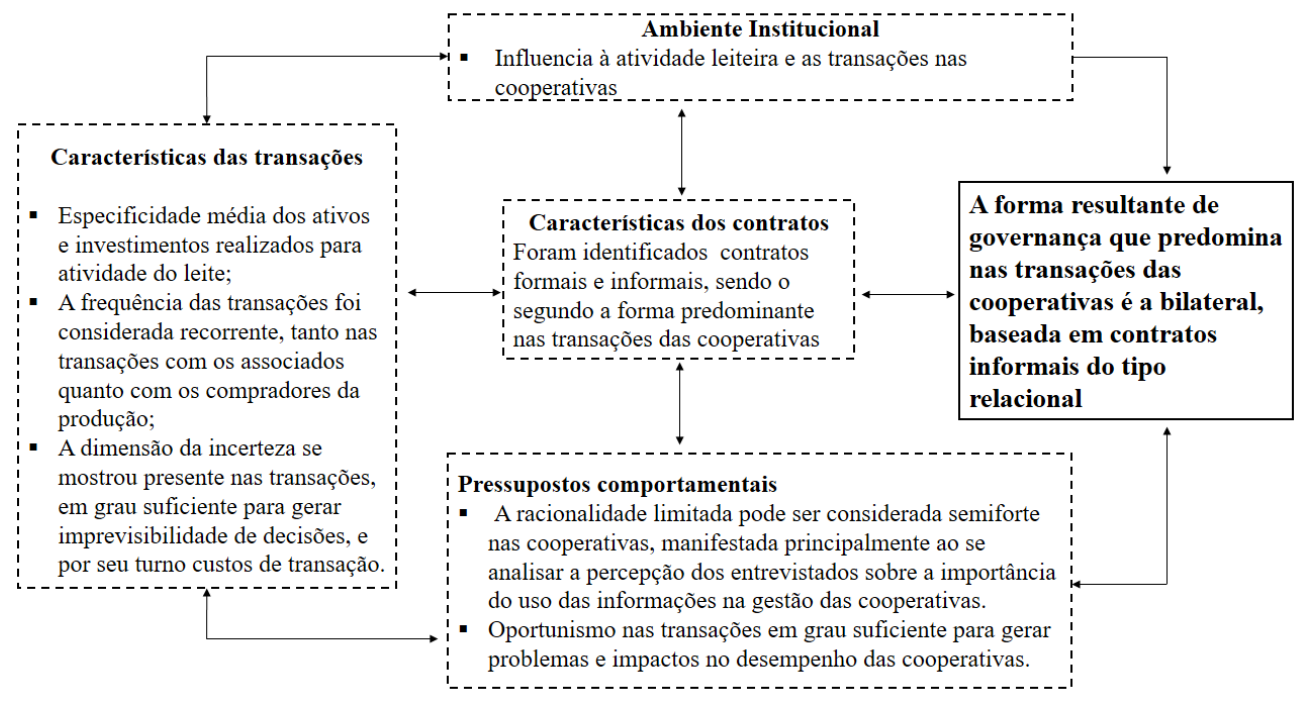

Fonte: Adaptada de Zylbersztajn (1995) com base nos dados de campo (2017). 
A análise estrutural discreta comparada demonstra que a estrutura de governança observada nas cooperativas está em concordância com as indicações teóricas da ECT, embora prevaleça a informalidade nos contratos realizados, a qual pode gerar ações oportunistas entre os agentes.

A presença dessa informalidade nos contratos não é exclusividade dos casos estudados. Bialoskorski Neto (2004) destaca que a base mais comum da relação entre os associados e as cooperativas no Brasil são contratos relacionais e informais. Não há, geralmente, obrigações comerciais ou incentivos para a participação econômica na atividade ou para prevenir ações oportunistas. Dessa forma, o associado não possui uma obrigação formal com a cooperativa; todavia, esse mesmo associado usufrui de todos os direitos possíveis no empreendimento cooperativo. Com os contratos informais e relacionais, é importante e essencial que o associado compreenda as vantagens do valor da cooperação, para que sua relação com a cooperativa não seja baseada apenas em interesses econômicos e, sim, em uma mutualidade para ambas as partes.

\section{Considerações finais}

O objetivo desse estudo foi analisar as estruturas de governança que predominam nas transações realizadas pelas organizações cooperativas de produção de leite a montante e a jusante no território Cantuquiriguaçu/PR. A investigação de campo revelou a existência de três grupos de cooperativas no cenário regional, conforme já relatado.

$\mathrm{Na}$ seção de resultados, foram apresentadas as razões para as decisões das cooperativas quanto à continuidade das operações ou ao seu encerramento, bem como os aspectos de conjuntura atual no mercado regional, expondo-se as dificuldades enfrentadas por essas organizações.

Além dos resultados apresentados, a realização do estudo permite uma observação final: não foram observadas, entre todas as cooperativas estudadas, diferenças significativas nas estruturas de governança que justificassem algumas terem se mantido no mercado e outras terem encerrado suas atividades, embora o oportunismo tenha sido citado como um dos principais motivos para o encerramento de atividades nas cooperativas não ativas na captação de leite dos produtores. Sob esse entendimento, destacase que a única cooperativa que realiza a industrialização do leite não apresentou diferenças nas características das transações e/ou percepções mais positivas sobre os pressupostos comportamentais em relação aos demais casos estudados. Ademais, todas as cooperativas apresentam elementos em comum, tais como: especificidades de ativos, incertezas, contratos predominantemente informais e presença de oportunismo.

Essa constatação pode levar à reflexão quanto aos limites deste estudo, o qual, por limitações de tempo e recursos, se concentrou apenas 
em analisar as transações sob a ótica das cooperativas, não abarcando, por exemplo, os outros elos do setor produtivo. Dessa forma, como estudos futuros e para buscar entender o comportamento de outros agentes do setor, sugere-se ampliar a pesquisa com os produtores de leite, captando a percepção e o comportamento destes em relação às formas de cooperação, e com as indústrias compradoras desse produto, analisando as relações e as estratégias adotadas por essas, a fim de ampliar o entendimento da cadeia produtiva e do mercado do leite.

\section{Referências}

ARBAGE, A. P. Custos de transação e seu impacto na formação e gestão da cadeia de suprimentos: estudo de caso em estruturas de governança híbridas do sistema agroalimentar no Rio Grande do Sul. Orientador: Antônio Domingos Padula. 2004. 280 f. Tese (Doutorado em Administração) - Programa de Pós-graduação em Administração, Universidade Federal do Rio Grande do Sul, Porto Alegre, 2004.

BANKUTI, S. M. S. Análise das transações e estruturas de governança na cadeia produtiva do leite no Brasil: a França como referência. Orientador: Hildo Meirelles de Souza Filho. 2007. 308 f. Tese (Doutorado em Engenharia de Produção) - Departamento de Engenharia de Produção, Universidade Federal de São Carlos, São Carlos, 2007.

BATALHA, M. O.; BUAINAIN, A. M.; SOUZA FILHO, H. M. Tecnologia de gestão e agricultura familiar. In: SOUZA FILHO, H. M.; BATALHA, M. O. (Org.). Gestão integrada da agricultura familiar. São Carlos: EduFSCar, p. 43$65,2005$.

BIALOSKORSKI NETO, S. Economia das organizações cooperativas: uma análise da influência da cultura e das instituições. Orientador: [?], 2004. 178 f. Tese (Livre-Docência em Economia das Organizações) - Faculdade de Economia, Administração e Contabilidade de Ribeirão Preto, Universidade de São Paulo, Ribeirão Preto, São Paulo, 2004.

BRANDÃO, J. B.; BREITENBACH, R. What are the main problems in the management of rural cooperatives in Southern Brazil? Land use Policy. v. 85, p. 121-129, 2019.

BREITENBACH, R. Estruturas de mercado de fatores e governança na cadeia produtiva do leite: um estudo de caso no município de Ajuricaba-RS. Orientador: Prof. Renato Santos de Souza. 2008. 178 f. Dissertação (Mestrado em Extensão Rural) - Programa de Pós-Graduação em Extensão Rural, Universidade Federal de Santa Maria, Santa Maria, 2008.

COASE, R. H. The nature of the firm. Economica, London, v. 4, n. 16, p. 386-405, nov. 1937.

CONSELHO DE DESENVOLVIMENTO DO TERRITÓRIO DA CANTUQUIRIGUAÇU (CONDETEC). Território Cantuquiriguaçu Paraná: Plano Safra territorial 2010/2013. Laranjeiras do Sul: CONDETEC, 2011.

MALHOTRA, N. Pesquisa de marketing: uma orientação aplicada. 4. ed. Porto Alegre: Bookmamn, 2006. 
MIGUEZ, G. C. Economía de las instituiciones: de Coase y North a Williamson y Ostrom. Ekonomiaz, Vigo, n. 77, p. 14-51, $2^{\circ}$ cuatrimestre, 2011.

SANGALLI, A. R.; HOLGADO, H. C. DA SILVA; SILVA, I. F. da; SCHLINDWEIN, M. M. Associativismo na agricultura familiar: contribuições para o estudo do desenvolvimento no assentamento rural Lagoa Grande em Dourados (MS), Brasil. Organizações Rurais \& Agroindustriais, Lavras, v. 17, n. 2, p. 225-238, 2015.

SCHNEIDER, S. Território, Ruralidade e Desenvolvimento. In: VELÁSQUEZ LOZANO, Fabio.; MEDINA, Juan Guillermo Ferro (Editores). (Org.). Las Configuraciones de los Territorios Rurales en el Siglo XXI. 1 ed. Bogotá/ Colombia: Editorial Pontifícia Universidad Javeriana, v. 1, p. 67-108, 2009.

SCHUBERT, M. N; WAQUIL, P. W. Análise dos custos de transação nas cooperativas da cadeia produtiva do leite no Oeste de Santa Catarina. Organizações Rurais \& Agroindustriais, Lavras, v. 16, n. 4, p. 435-449, 2014.

SIMIONI, F. J; SIQUEIRA, E. S.; BINOTTO, E; SPERS. E. E.; ZILDA ARAÚJO, Z. A. de. Lealdade e oportunismo nas cooperativas: desafios e mudanças na gestão. Revista de Economia e Sociologia Rural, Piracicaba, v. 47, n. 3, p. 739$765,2009$.

SIMON, H. A. Rationality as process and as product of thought. American Economic Review, Pittsburgh, v. 68, n. 2, p. 1-16, may. 1978.

WILKINSON, J. Estudo da competitividade da indústria brasileira: o complexo agroindustrial. Rio de Janeiro: Forense Universitária; UFRRJ, 1996.

WILLIAMSON, O. E. Las instituiciones económicas del capitalismo. Ciudad del Mexico: Fondo de Cultura Económica, 1989.

WILLIAMSON, O. E. Comparative economic organization: the analysis of discrete structural alternatives. Administrative Science Quarterly, Ithaca, v. 36, n. 2, p. 269-296, 1991.

WILLIAMSON, O. E. Transaction cost economics and organization theory. Journal of Industrial and Corporative Change, Oxford, n. 2, p. 107-156, 1993.

WILLIAMSON, O. E. The mechanisms of governance. New York: Oxford University Press, 1996.

WILLIAMSON, O. E. As instituições econômicas do capitalismo: firmas, mercados e relações contratuais. São Paulo: Pezco, 2012.

WORDCLOUDS. 2017. Disponível em: <https://www.wordclouds.com/>. Acesso em: 10 mar. 2017.

ZHANG, C.; LI, J. J.; HUANG, Y. Sustaining relationships after opportunism and misunderstanding: the role of formalization and socialization. Marketing Letter, v. 28, n. 2, p. 305-319, 2017.

ZYLBERSZTAJN, D. Estruturas de governança e coordenação do agribusiness: uma aplicação da nova economia das instituições. Orientador: [?], 1995. 241 f. Tese (Doutorado em Economia, Administração e Contabilidade) Faculdade de Economia, Administração e Contabilidade, Universidade de São Paulo, São Paulo, 1995. 
ZYLBERSZTAJN, D; GIORDANO, S. R. Coordenação e Governança de sistemas agroindustriais. In: ZYLBERSZTAJN, D.; NEVES, M. F.; CALEMAN, S. M. DE QUEIROZ (Org.). Gestão de sistemas de agronegócios. São Paulo, FEA/USP, p. 1-22, 2015.

Recebido: 08/01/2019.

Aceito: 12/08/2019. 


\title{
TRANSACTIONS AND GOVERNANCE STRUCTURES IN COOPERATIVE ORGANIZATIONS IN THE MILK ACTIVITY OF TERRITORY CANTUQUIRIGUAÇU /PR
}

\begin{abstract}
Based on theoretical contributions of Transaction Cost Economics (TCE) and using the method of Comparative Discrete Structural Analysis for data interpretation, the objective of this paper was to analyze the governance structures that predominate in the transactions carried out by cooperative organizations of milk production in the territory of Cantuquiriguaçu/PR. In the field research we found the existence of three distinct groups of cooperatives in this territory. The first one is composed of seven active cooperatives in milk collection, with upstream and downstream operations in this activity. Another one composed of three non-active cooperatives in milk collection, but which are active with their associates. The third one composed of three cooperatives that had been liquidated, which were discarded because of the impossibility of contacting some of the legal responsible members. In the three non-active cooperatives, we identified that market competition (prices, pressure from other companies etc.), lack of value added to the product, low negotiating power and opportunism of agents were considered as determining factors to end milk production in the region. On the other hand, research on those active cooperatives in milk collection revealed that the governance structure that predominates in their transactions is bilateral or classified as hybrid, based on contractual relationships which are predominantly informal and relational. Through the method of Comparative Discrete Structural Analysis it is possible to conclude that this form of governance in active cooperatives is in agreement with theoretical indications of TCE.
\end{abstract}

Keywords: Family farming. Cooperative organizations. Dairy farming. Governance structure.

\section{TRANSACCIONES Y ESTRUCTURAS DE GOBERNANCIA EN ORGANIZACIONES COOPERATIVAS EN LA ACTIVIDAD LECHERA DEL TERRITORIO CANTUQUIRIGUAÇU/PR}

\begin{abstract}
Resumen
Apoyado en los aportes teóricos de la Economía de los Costos de Transacción (ECT) y utilizando el método de Análisis Estructural Discreta Comparada (AEDC) para la interpretación de los datos, el objetivo del artículo fue analizar las estructuras de gobernanza que predominan en las transacciones realizadas por las organizaciones cooperativas de producción de leche en el territorio Cantuquiriguaçu/PR. La investigación de campo reveló la existencia de tres grupos distintos de cooperativas en este territorio. Un primer compuesto por siete cooperativas activas en la captación de leche, con operaciones ascendentes y aguas abajo en la actividad. Otro compuesto por tres cooperativas no activas en la captación de leche, pero actuantes junto a sus asociados. Y un tercer compuesto por tres cooperativas que habían sido liquidadas, las cuales fueron descartadas del estudio por la imposibilidad de contacto con alguno de los responsables legales. En las tres cooperativas no activas, la investigación identificó que la competencia de mercado (precios, presión de otras empresas etc.), la falta de agregación de valor al producto, el bajo poder de negociación y el oportunismo de los agentes, se consideraron factores determinantes de las cuales se concluye la actividad de captación de leche en la región. La investigación sobre aquellas cooperativas que permanecían activas en la captación de leche reveló que la estructura de gobernanza que predomina en sus transacciones es la bilateral o también clasificada como híbrida, basada en relaciones contractuales predominantemente informales y del tipo relacional. Utilizando el método de la AEDC se puede concluir que esa forma de gobernanza observada en las cooperativas activas está en concordancia con las indicaciones teóricas de la ECT.
\end{abstract}

Palabras clave: Agricultura familiar. Organizaciones cooperativas. Ganadería lechera. Estructura de gobernanza. 